\title{
Experimental and Numerical Study in Horizontal Tube by using Swirl Device
}

\author{
${ }^{1}$ Muna S. Kassim, ${ }^{2}$ Wajeeh Kamal Hasan, ${ }^{3}$ Hasanen Mohammed Hussen and ${ }^{4}$ Laith Jaafer Habeeb \\ ${ }^{1}$ Department of Mechanical Engineering, AL-Mustansiriyah University, Baghdad, Iraq \\ munasaljabri@gmail.com \\ ${ }^{2}$ Department of Refrigeration and Air Conditioning Engineering, \\ Al-Rafidain University Collage, Baghdad, Iraq \\ dr.wajeeh21@gmail.com \\ ${ }^{3}$ Department of Mechanical Engineering, \\ hasanen.alsaady@yahoo.com \\ ${ }^{4}$ Training and Workshop Center, University of Technology, Baghdad, Iraq \\ laithhabeeb1974@gmail.com
}

\begin{abstract}
Heat exchanger performance can be basically evolved by many heat transfer enhancement techniques. The current experimental and numerical investigations disclose the use of different twisted tapes inserted in a single tube heat exchanger for better fluid mixing which produces a higher rate of heat transfer comparing to that of smooth tube. The tube is made of from copper material of $2.3 \mathrm{~cm}$ inner diameter and $100 \mathrm{~cm}$ length. The experimental work is conducted in an insulated horizontal circular tube in the laminar flow region to test the influence of tap-inserts on the heat transfer enhancement and pressure drop, under constant heat flux condition. Two configurations of twisted tapes that are also fabricated from copper material with different Twist Ratios ( $\mathrm{TR}=4$ and 6 ) are used. The numerical study is performed using the ANSYS Fluent 15.0 based on the finite volume technique for solving the governing equations, for different values of Reynolds number with water being as a working fluid.
\end{abstract}

Key words: Heat transfer enhancement, laminar flow, circular tube, twisted tape, water, smooth

\section{INTRODUCTION}

Heat exchangers are employed as a basic element in most engineering thermal applications. The design of a heat exchanger is indeed intricate as it requires an accurate analysis of thermal and frictional performance and then the economic aspect of the equipment. Therefore, the big defy in designing such device is to produce a consolidate equipment utilizing appropriate techniques for achieving higher rates of heat transfer and lower pumping cost (Liu and Sakr, 2013).

The existing relevant literature reveals that there have been many papers reporting numerical and experimental results about heat transfer augmentation techniques using twisted tape inserts, however, most of them have been limited to simple geometries. Agarwal and Rao (1996) investigated experimental forced convection fluid flow in a horizontal circular tube using servotherm oil with Prandtl number $(\mathrm{Pr}=195-375)$ and for Reynold number and Twist Ratio ranging of $(\mathrm{Re}=70-4000)$ and $(\mathrm{TR}=$ 2.41-4.84), respectively, under uniform wall temperature heating and cooling condition. The results showed a good enhancement in Nusselt number (1.21-3.7) and
(2.28-5.35) times the plain tube values on the basis of constant pumping power and constant flow rate, respectively. However, an appreciable increase in the friction factor (3.13-9.71) was found. They proposed empirical correlations for heat transfer and friction factor for practical applications.

Saha and Dutta (2001) examined experimentally convective laminar flow in a circular tube, induced by a regularly spaced twisted tape for a wide range of Renolys number $(145<\operatorname{Re}<1480)$ and a Twist Ratio ranging from $(\mathrm{TR}=1.92-5.0)$ with water being as a working fluid $(4.5<\operatorname{Pr}<5.5)$. They concluded that there is a severe drop in the friction factor corresponding of the reduction in Nusselt number. They also found that at a constant pumping power, the twisted tape with multiple turns can enhance the thermal-hydraulic performance compared with that for a single turn twisted tape. Al-Fahed et al. (1998) conducted an experimental study to calculate the heat transfer coefficients and friction factors inside a single shell-and-tube heat exchanger fitted with microfin and with a twisted tape and compare their results with those for a plain tube. During the investigation, they used three variant twist ratios with two different widths. The

Corresponding Author: Muna S. Kassim, Department of Mechanical Engineering, AL-Mustansiriyah University, Baghdad, Iraq munasaljabri@gmail.com 
working fluid in the heat exchanger was oil where the steam was used as a heat source to obtain a uniform temperature on the tube wall. They observed that for a small Twist Ratio (TR $=5.4$ ), the loose-fit twisted tape is a desirable choice owing to the easiness of installation and removing for cleaning process but with respect to other twist ratios, it was found that the tight-fit twisted tape produces higher thermal performance than that produced by the loose-fit twisted tape.

Heat transfer of laminar flow of water in a vertical copper pipe cooled by air and fitted with a twisted tape at different pitch values was experimentally investigated by Klaczak (2000). The ranges of Reynolds number and twist ratio were selected to be $(110=\mathrm{Re}=1500)$ and $(\mathrm{TR}=1.62-5.29)$, respectively. The results demonstrated that there is an increase in heat transfer rate with an increase in the pitch value of twisted tape. Liao and Xin (2000) reported experimental data on heat transfer and friction factor in a circular tube induced with 3D internal extended surfaces. It was concluded that the friction factor decreases considerably by replacing the continuous twisted tape with segmented inserts with a little decrease in Stanton number. Saha and Dutta (2001) investigated experimentally Nusselt number and pressure drop of laminar swirl flow generated by using a twisted tape inside a circular tube for Prandtl number $(205<\operatorname{Pr}<518)$. They compared the results of two types, i.e., short length and full length of twisted tapes and observed that at a constant pumping power, the short-length tape is a better choice for both heat transfer augmentation and pressure drop than the full-length tape. This is because that the short insert disturbs and decays slowly the generated swirl flow downstream the tube which enhances the heat transfer coefficient and reduces the fraction factor. Kapatkar et al. (2010) conducted an experimental study to calculate the heat transfer and friction factor of laminar flow in a smooth tube fitted with full length twisted tape inserts for the range of Reynolds number $(\operatorname{Re}=200-2000)$. Three different tap material were used namely aluminum, stainless steel and insulated tape to examine the influence of the tape-fin at Twist Ratio ranging ( $\mathrm{TR}=5.2-3.4$ ) under constant heat flux condition. The results showed that the full length twisted tapes increases significantly the average Nusselt number as compared to plain tube. It was also shown that the maximum improvement in Nusselt number for aluminum tapes, Stainless steel tapes and insulated tapes, range from $50-100,40-94,40-67 \%$, respectively.

A comparative numerical study between a center-cleared twisted tape and a short-width twisted tape was performed by Guo et al. (2011) for a better understanding for laminar tubular flows and more enhancement in heat transfer. Their numerical results revealed that a noticeable improvement in heat transfer can be achieved by using center-cleared twisted tapes but with an appropriate central clearance ratio. It was found that the augmentation in the thermal performance factor of heat exchanger inserted with center-cleared twisted tape can be ranging between (7-20\%) comparing with the classical twisted tape. Zhang et al. (2012) studied numerically the thermo-hydraulic characteristics in a circular single tube fitted with triple and quadruple twisted tape inserts under laminar flow, i.e., ( $\operatorname{Re}=300-1800)$. The results showed that the tubes induced with triple and quadruple twisted tapes produce higher heat transfer rates up to 171 and $182 \%$, respectively as compared to the plain tube with a variation in the thermal performance factor between 1.64 and 2.46. In addition, these increases caused a considerable raise in the friction factor of around (4 and 7) times, respectively. Salman et al. (2013) reported numerical results about laminar swirl flows in a tube fitted with two types of inserts, i.e., elliptic-cut and conventional twisted tape, for the range of Reynolds number of $(\operatorname{Re}=200-2100)$. The study also focused on the influence of twist ratio $(2.93,3.91$ and 4.89) and cut depth $(0.4,0.8$ and $1.4 \mathrm{~cm})$ on the thermal and frictional profiles in the tube. The simulated results demonstrated that the Nusselt number and pressure drop in the tube equipped with the conventional twisted tape are much lower than those induced with the elliptic-cut twist tape.

Bhattacharyya et al. (2013) provided empirical data and correlations about average Nusselt number and friction factor for convective laminar flow inside a round-section duct induced with center-cleared twisted-tape and possessing integral transverse ribs. They observed that the combination use of twisted tapes with transverse ribs awards greater heat transfer enhancement than each individual technique acting alone but up to an assure value of a centre-clearance.

This research presents experimental and numerical investigations of the influence of using different sorts of twisted tapes, namely $\mathrm{V}$-cut and alternate axis on the profile of fluid flow and augmentation of heat transfer. Experimentally, the test rig was built for a broad range of Reynolds number $(1056=\mathrm{Re}=2002)$ under a high steady heat flux ranging $\left(2420-12261 \mathrm{~W} / \mathrm{m}^{2}\right)$, using up-to-date measuring apparatuses and instruments that can be calibrated precisely.

\section{MATERIALS AND METHODS}

Experimental apparatus: The experimental rig is demonstrated schematically in Fig. 1. The rig consists of the following fundamental parts and measuring tools:

- Tube section

- Temperature recorder

- Pump

- Water tank

- Thermocouples 


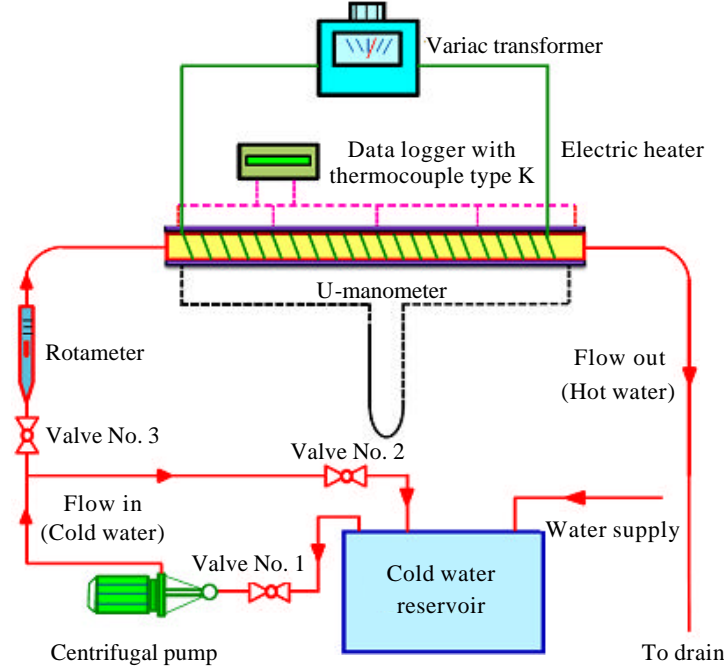

Fig. 1: Schematic diagram of experimental test rig

- Variac transformer

- Rotameter

- Globe valves

- U-tube manometer

- Voltmeter and ammeter used to measure the power of the heater

The following procedure was performed during the experiments as follows: firstly, the electric heater is switched on and the desired temperature is maintained using a temperature controller. Then the water pump is switched on and the cold water flow rate to the test section is adjusted using a by-pass valve. During laminar flow, the hot water flows through a flow meter of 60-100 $\mathrm{L} / \mathrm{h}$ with an increase of $10 \mathrm{~L} / \mathrm{h}$. After that, the distilled water at $20^{\circ} \mathrm{C}$ is pumped to the test section where it is exposed to a uniform heat flux from the heater and the heated water is drained out allowing the cold water supplied to the next test. The steady state is obtained within about $1 \mathrm{~h}$ for the first run and within about (25-30 $\mathrm{min})$ for the subsequent runs. Repeating the aforementioned steps for the entire range of flow rate for the pain tube first and with both $\mathrm{V}$-cut and alternate axis inserts.

Numerical simulation: The swift and abrupt progress of numerical technique and software such as CFD codes has enabled the engineers and analysts to solving highly complicated engineering thermal problems. Recently, the CFD codes are used for modeling and simulating efficiently fluid flows and heat characteristics for better understanding of complex hydrodynamics without the help of instruments for measuring variant flow variables at desired locations in many industrial processes. Great endeavors have been made to employ the numerical simulating for designing convection heat transfer devices and studying the detailed flow behaviors and heat transfer augmentation and degradation, e.g., heat exchangers that take place inside tubes. In the literature, simulations using CFD for twisted tape are rarely reported. In the present research, CFD modeling using Fluent 15.0 is carried out in order to predict the temperature and velocity distribution for a plain tube and tube equipped with V-cut and alternate axis twisted tapes.

Mesh generation and distribution: The present study uses an unstructured mesh to discretize the region of computation into a finite number of control volumes by utilizing the Finite-Volume Method (FVM). The structured mesh is eliminated because it is relevant only for uncomplicated problems and it becomes inadequate and time depleted for sophisticated geometries. Indeed, the generation and refinement of meshing system are probably the most important part in any of the computer simulations for prediction of fluid flow and heat transfer in such sophisticated geometries. Thus, together the distribution and the density of the grid lines have the appreciable roles for significant precision. In the unstructured meshing, the pattern of connections varies from point to point. Also the connectivity of the mesh must be explicitly described by an appropriate data structure. Several element forms for meshing topology can be used in Fluent Software. In fact, the form of element considerably restricts the number of grid nodes and the node mode in relation to element shapes (Rebay, 1993). In this study, a triangular element form is employed for the 2D surface mesh and a tetrahedron element form is used for the 3D geometry mesh due to its priority in the complex geometries.

Convergence: For the present study, the iterative solution continues in a periodic sequence until an absolute convergence criterion of is accomplished for every field variables. The values of convergence criterion for each variable are taken into account as follow: for pressure $\left(1 \times 10^{-4}\right)$, for velocities $\left(1 \times 10^{-6}\right)$ and for energy $\left(1 \times 10^{-7}\right)$.

Governing equations: The governing equations for continuity, momentum and energy must be solved for laminar flow inside the inner region of tube.

Continuity equation:

$$
\frac{\partial \mathrm{u}}{\partial \mathrm{x}}+\frac{\partial \mathrm{v}}{\partial \mathrm{x}}+\frac{\partial \mathrm{w}}{\partial \mathrm{x}}=0
$$


Momentum equation:

$$
\begin{gathered}
\rho\left(u \frac{\partial u}{\partial x}+v \frac{\partial u}{\partial y}+w \frac{\partial u}{\partial z}\right)=-\frac{d p}{d x}+\mu\left(\frac{\partial^{2} u}{\partial x^{2}}+\frac{\partial^{2} u}{\partial y^{2}}+\frac{\partial^{2} u}{\partial z^{2}}\right) \\
\rho\left(u \frac{\partial v}{\partial x}+v \frac{\partial v}{\partial y}+w \frac{\partial v}{\partial z}\right)=-\frac{d p}{d x}+\mu\left(\frac{\partial^{2} v}{\partial x^{2}}+\frac{\partial^{2} v}{\partial y^{2}}+\frac{\partial^{2} v}{\partial z^{2}}\right) \\
\rho\left(u \frac{\partial w}{\partial x}+v \frac{\partial w}{\partial y}+w \frac{\partial w}{\partial z}\right)=-\frac{d p}{d z}+\mu\left(\frac{\partial^{2} w}{\partial x^{2}}+\frac{\partial^{2} w}{\partial y^{2}}+\frac{\partial^{2} w}{\partial z^{2}}\right)
\end{gathered}
$$

Energy equation:

$$
\rho C_{p}\left(u \frac{\partial T}{\partial x}+v \frac{\partial T}{\partial y}+w \frac{\partial T}{\partial z}\right)=k\left(\frac{\partial^{2} \mathrm{~T}}{\partial x^{2}}+\frac{\partial^{2} T}{\partial y^{2}}+\frac{\partial^{2} T}{\partial z^{2}}\right)
$$

\section{RESULTS AND DISCUSSION}

\section{Experimental results analysis}

Twisted tape thermal effect: Figure 2 and 3 show the influence of the inserting different tapes inside the plain tube for two values of twisting ratio 6 and 4, respectively and for the whole range of Reynolds number. Generally, one can see that Reynolds number and the twist ratio have considerable positive and negative impacts on Nusselt number, respectively, thus as Reynolds number increases or the twist ratio decreases, Nusselt number is clearly increased, for all types of twisted tapes. In

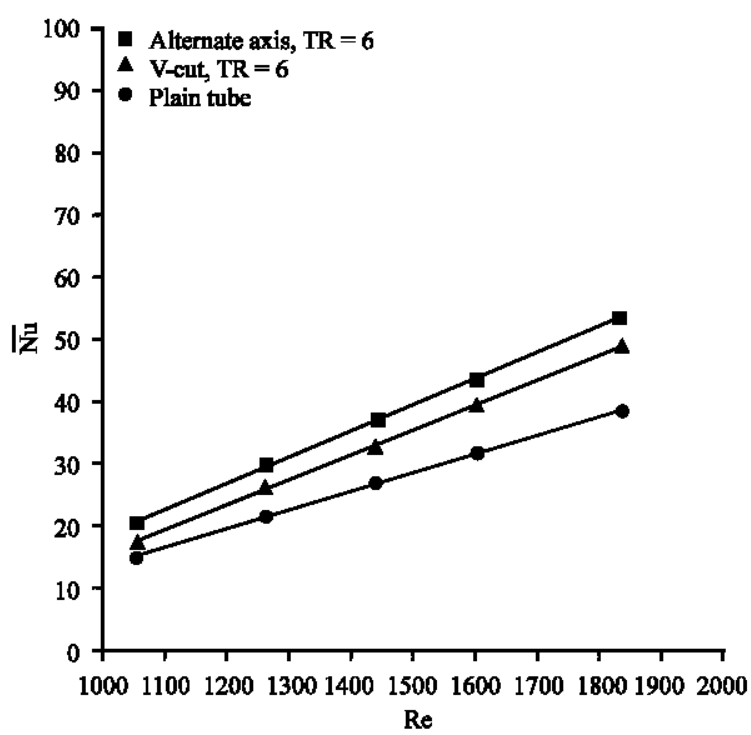

Fig. 2: The variation of average Nusselt number with Reynolds number for distilled water at Twist Ratio $(\mathrm{TR}=6)$ addition, it is also seen that the heat transfer rate increases noticeably, if the alternate axis twisted tape is used instead of the V-cut twisted tape, for the two values of Twist Ratios ( $\mathrm{TR}=4,6$ ). This heat transfer enhancement results from the secondary and/or rotational flows that arise owing to the use of twisted tape.

Figure 4 and 5 demonstrate the augmentation in heat transfer represented by the following Nusselt number

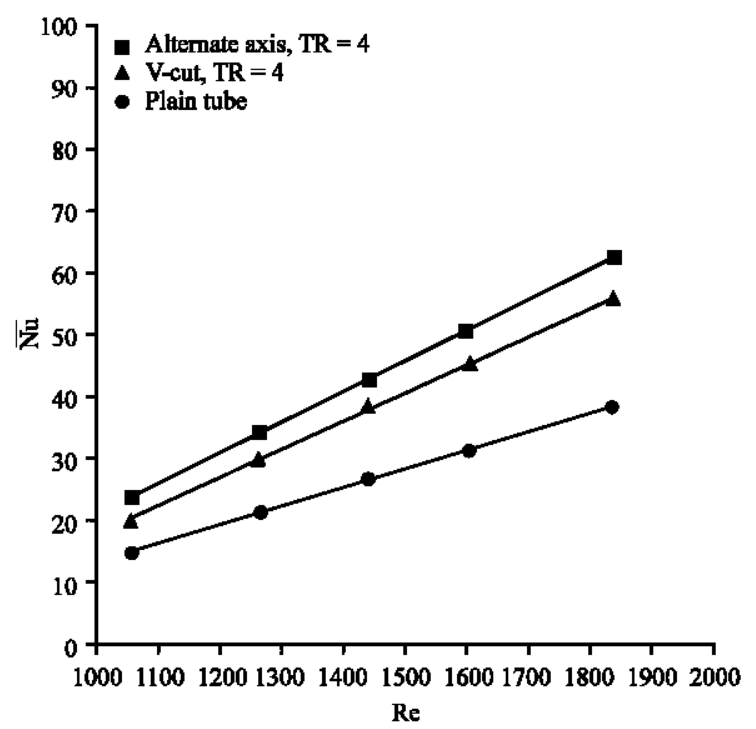

Fig. 3: The variation of average Nusselt number with Reynolds number for distilled water at Twist Ratio $(\mathrm{TR}=4)$

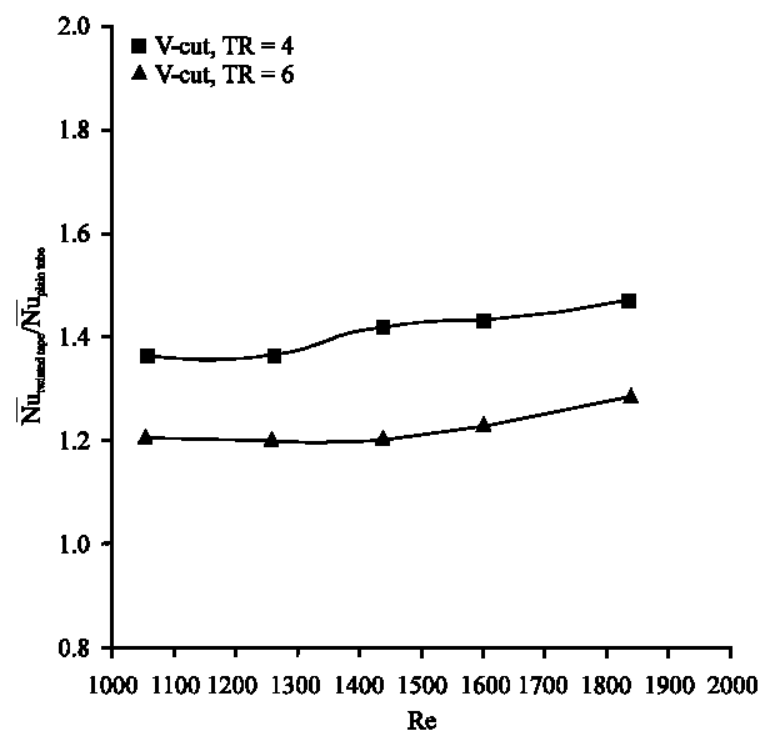

Fig. 4: The variation of Nusselt number ratio with Reynolds number for distilled water in a tube inserted with a V-cut twisted tape 


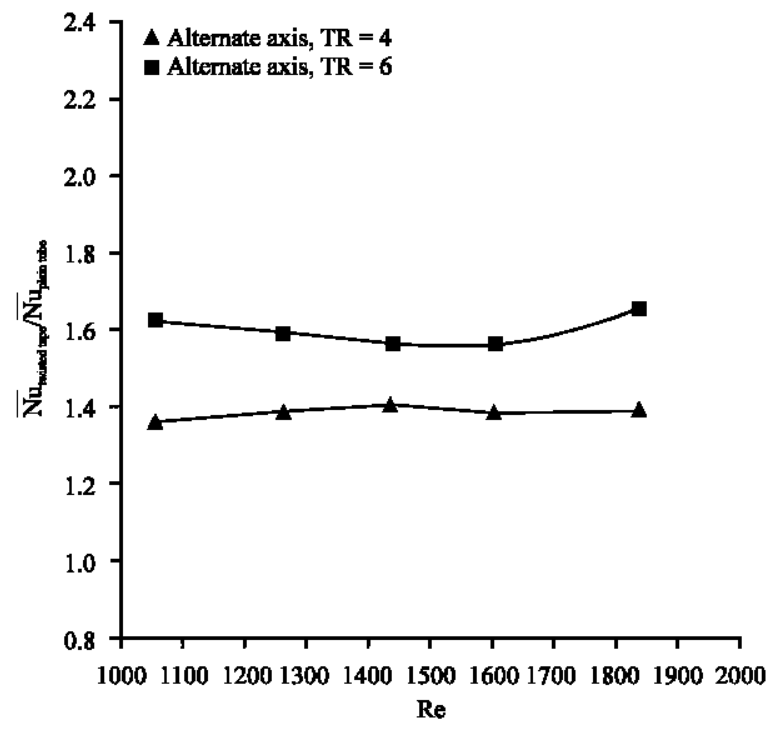

Fig. 5: The variation of Nusselt number ratio with Reynolds number for distilled water in a tube inserted with an alternate axis twisted tape

ratio $\left(\mathrm{Nu}_{\text {twisted tape }} \mathrm{Nu}_{\text {plain tube }}\right)$ against Reynolds number, for the $\mathrm{V}$-cut and the alternate axis twisted tapes at the two twist ratios.

It is obvious in Fig. 4 that the heat enhancement $\left(\mathrm{Nu}_{\text {twisted tape }} / \mathrm{Nu}_{\text {plain tube }}\right)$ increases as the twist ratio reduces when using the V-cut twisted tape. This is because the reduction in the twist ratio increases in intensity of the swirl flows in the tube which enhances the heat transfer. It is shown that the supreme enhancement (1.47) is occurred at the Twist Ratio of $(\mathrm{TR}=4)$ and Reynolds number of (1834).

On the other hand, Fig. 5 displays that as the twist ratio increases the augmentation in heat transfer decreases when utilizing the alternate axis twisted tape. Thus, the maximum Nusselt number ratio (1.65) occurs at the Twist Ratio of TR $=6$ and at the same Reynolds number of 1834 .

Twisted tape hydrodynamic effect: Figure 6 shows the relation between the friction factor and Reynolds for the two types of tape relative to the plain tube. It is noted that the friction factor values decrease with an increase in Reynolds number and twist ratio. It can be seen that there is a significant rise in the friction factor values when replacing the V-cut twisted tape by alternate axis twisted tape, for all the Twist Ratios (TR $=4,6$ ).

The variation of friction factor ratio with Reynolds number for the V-cut tape is represented in Fig. 7 for both $(\mathrm{TR}=4,6)$. We noticed that as Reynolds number and twist ratio increase the friction factor ratio decreases. The

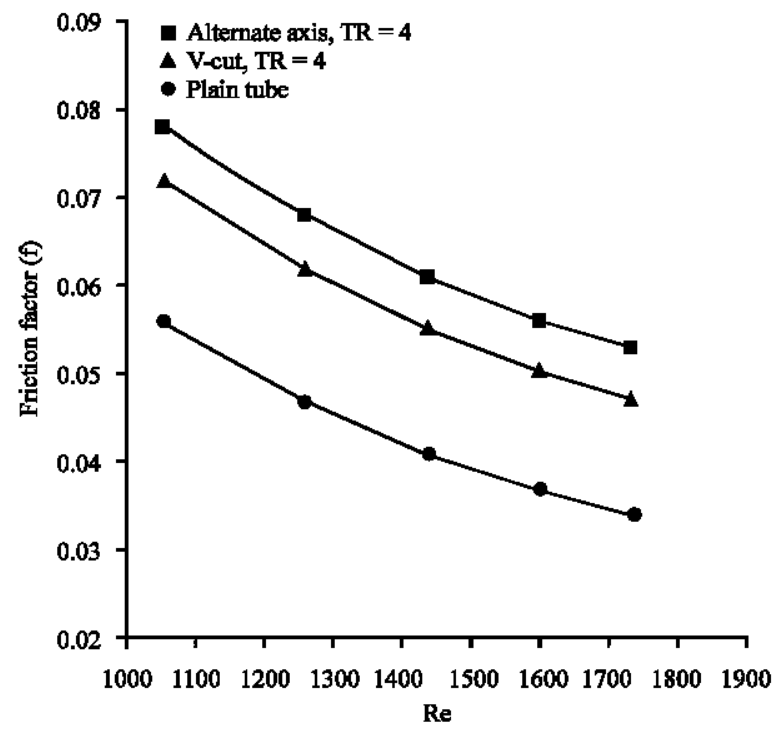

Fig. 6: The relation between friction factor and Reynolds number for variant types of twisted tapes at $(\mathrm{TR}=4)$

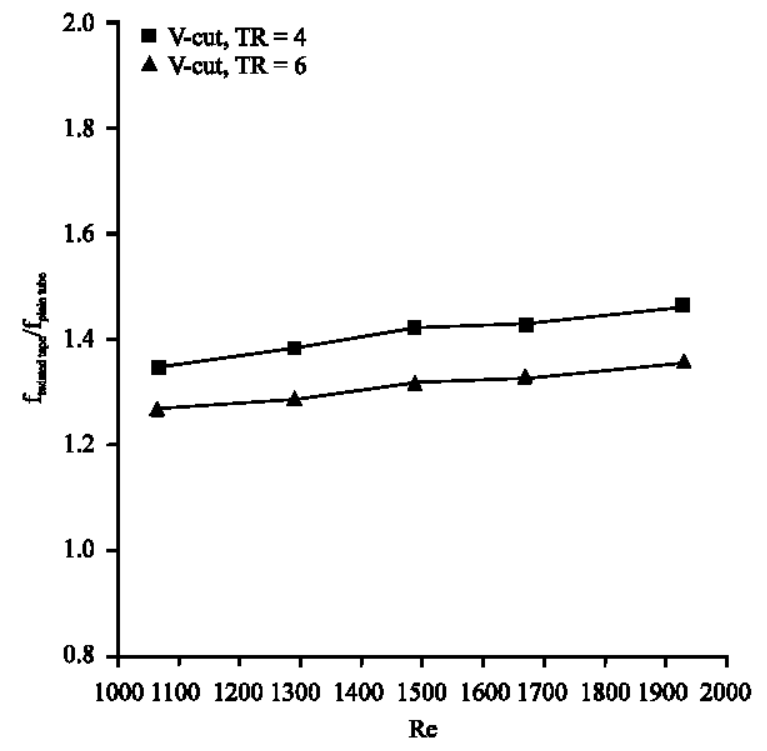

Fig. 7: Friction factor ratio with Reynolds number for the $\mathrm{V}$-cut twisted tape at different TR

maximum increase in the friction factor ratio is (1.4) which is obtained at Twist Ratio $(\mathrm{TR}=4)$ and Reynolds number 1834.

The relation between the pressure drop represented by the fraction factor ratio and Reynolds number for the alternate axis tape is illustrated in Fig. 8. The figure clearly clarifies that as Reynolds number and twist ratio increase the friction factor ratio decreases. The drastic friction factor ratio which its 


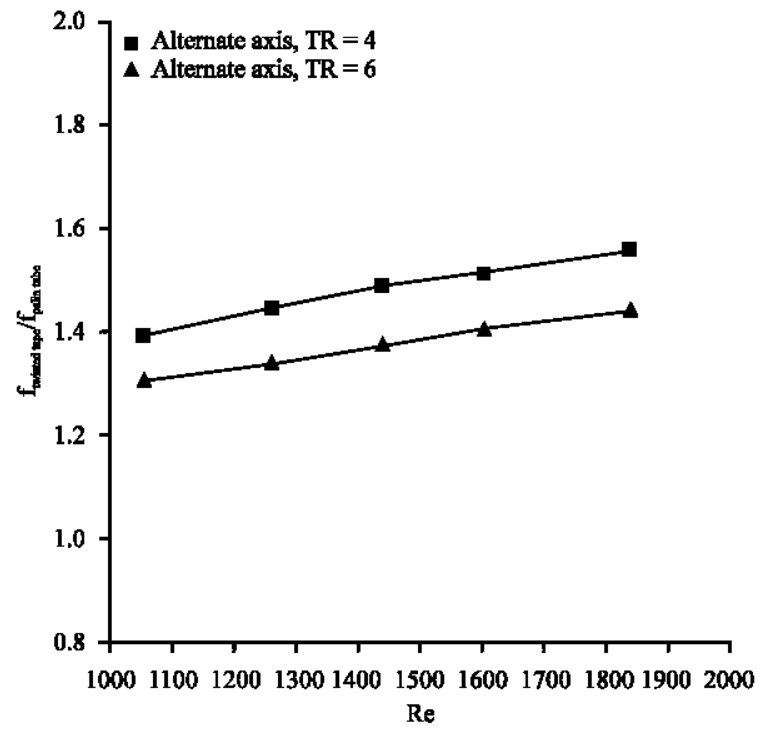

Fig. 8: Friction factor ratio with Reynolds number for the alternate axis twisted tape at different TR

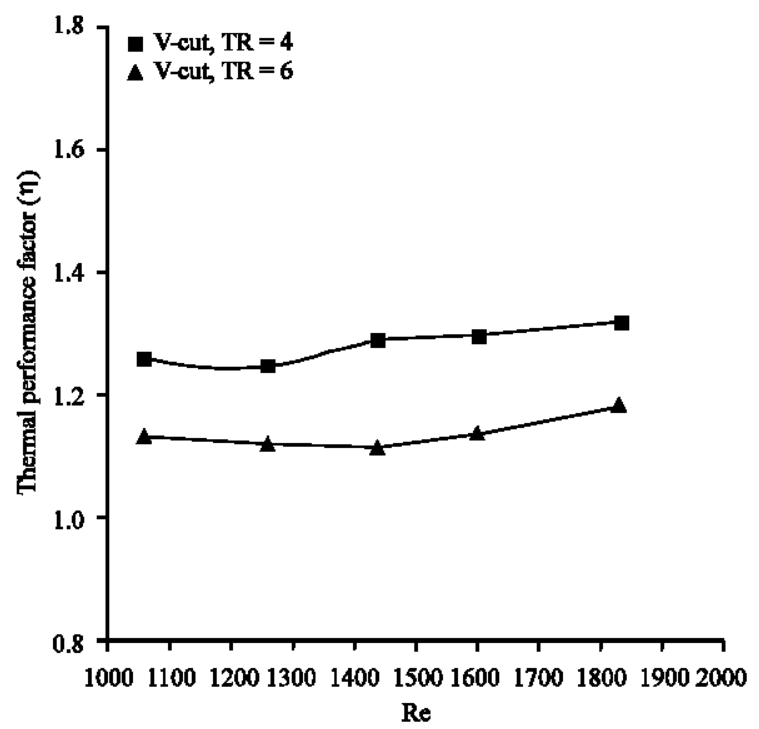

Fig. 9: Thermal performance factor $(\eta)$ versus Reynolds number for the $\mathrm{V}$-cut twisted tape at different $\mathrm{TR}$

value equals to 1.6 , happens at the higher Reynolds number of 1834 and at the Twist Ratio of $(\mathrm{TR}=4)$.

Thermal performance factor evaluation: Figure 9 and 10 depict the variation in thermal performance factor with Reynolds number for the two types of twisted tape and with the two Twist Ratios (TR = 4, 6). From Fig. 9, for the $\mathrm{V}$-cut twisted tape, the top thermal performance (1.31) can be obtained at the Twist Ratio of $(\mathrm{TR}=4)$ and Reynolds number 1834.

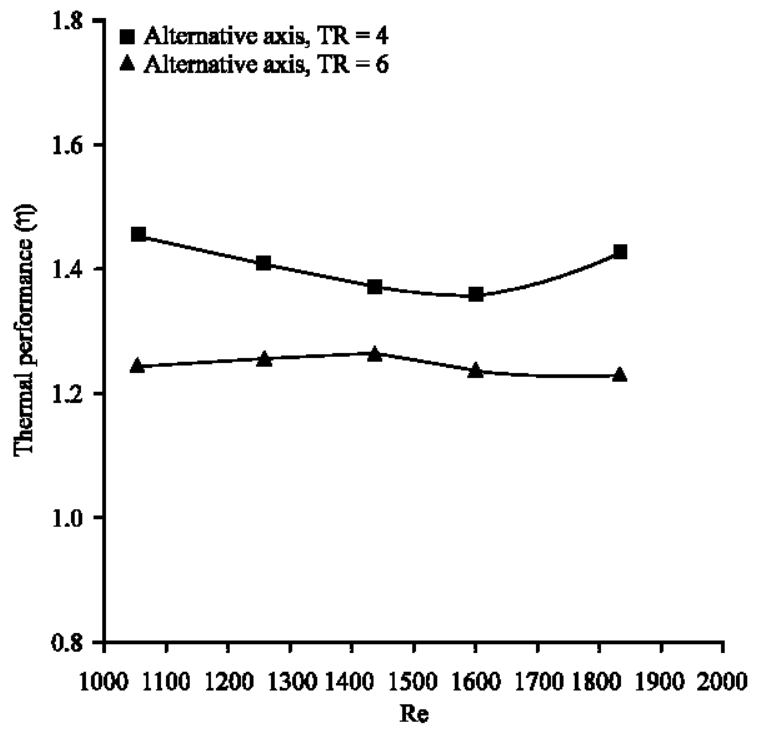

Fig. 10: Thermal performance factor $(\eta)$ versus Reynolds number for the alternate axis twisted tape at different TR

In addition, Fig. 10 shows that the optimum index of thermal performance (1.42) also can be taken place at the same Twist Ratio and Reynolds number $(\mathrm{TR}=4)$ and $(\operatorname{Re}=1834)$, respectively. The reason of the maximum heat augmentation is happened at $(\mathrm{TR}=4)$ is that at this ratio the further gain in Nusselt number conquers the growing in friction factor.

\section{Numerical results analysis}

Validation of CFD results: In order to clarify the capability of the CFD code in predicting the behavior of fluid flow and the profile of heat transfer in the plain tube equipped with twisted tape inserts, a validation of all experiment tests is achieved. So that, we can complete the hardest and more complicated part, the most important part in this study. The simulated average Nusselt numbers across the tube versus $(\mathrm{Re})$ are compared with those obtained from experiments as shown in Fig. 11 and 12 . From these figures, it is observed that the simulated values are matching with the experimental values within \pm 10 and $\pm 9 \%$ for $\mathrm{V}$-cut and alternate axis twisted tape, respectively. This deviation could be related to the losses associated with the experimental part which are not taken into account theoretically. However, both results have the same behavior and the differences are with acceptable values.

Velocity vectors: Figure 13 shows the velocity vector at different sections along the tube for $\mathrm{V}$-cut twisted tape. 


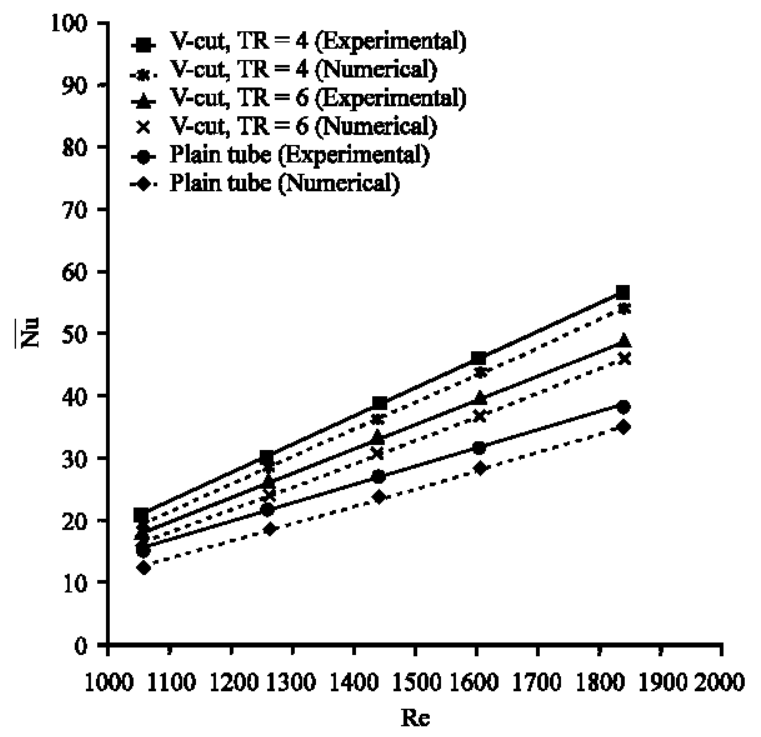

Fig. 11: Comparison of numerical and experimental results in a tube with V-cut twisted tape

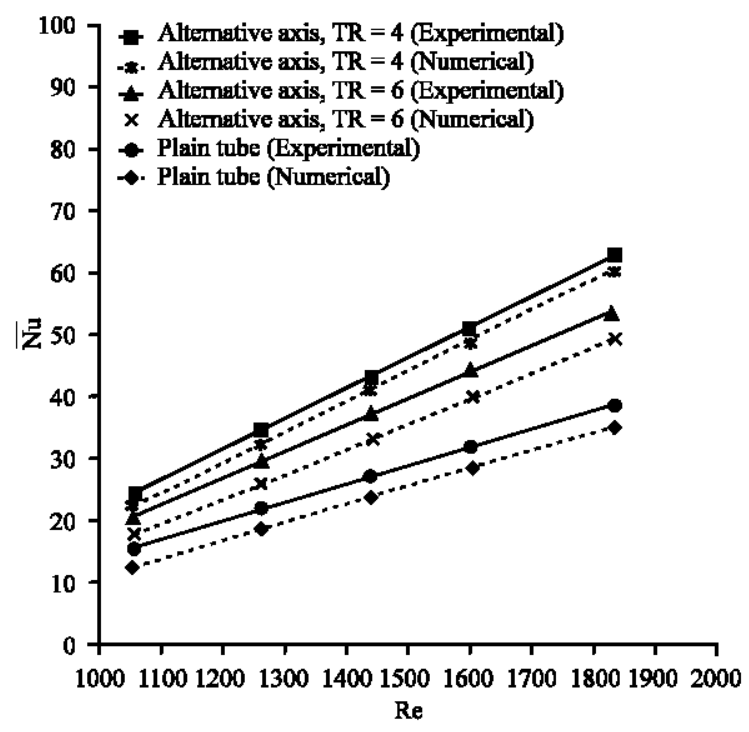

Fig. 12: Comparison of numerical and experimental results in a tube with alternate axis twisted tape

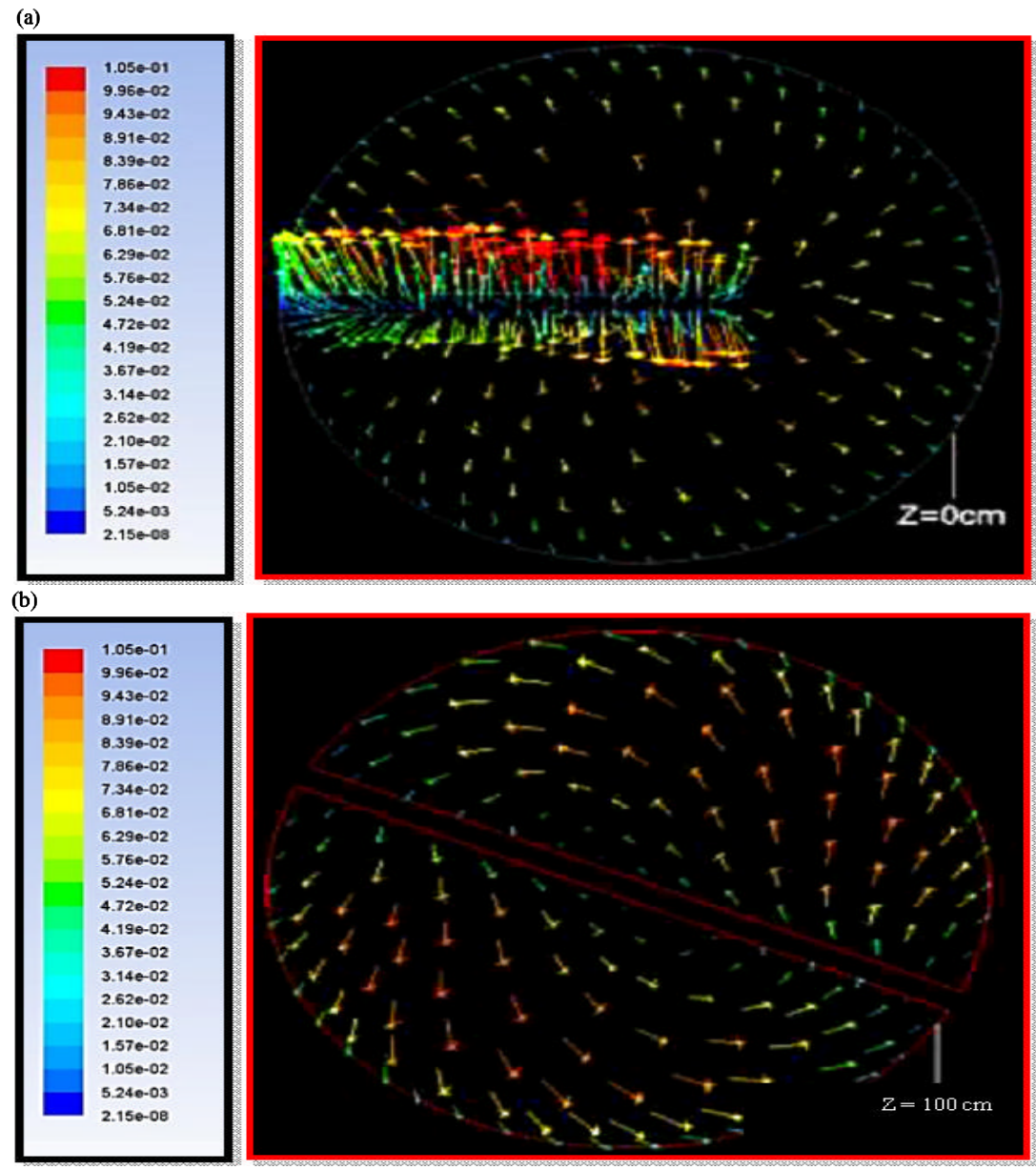

Fig. 13: a, b) Velocity vector in $(\mathrm{m} / \mathrm{sec})$ at locations of V-cut twisted tape along the test section with $(\mathrm{Re}=2002$, TR $=4)$ 
(a)

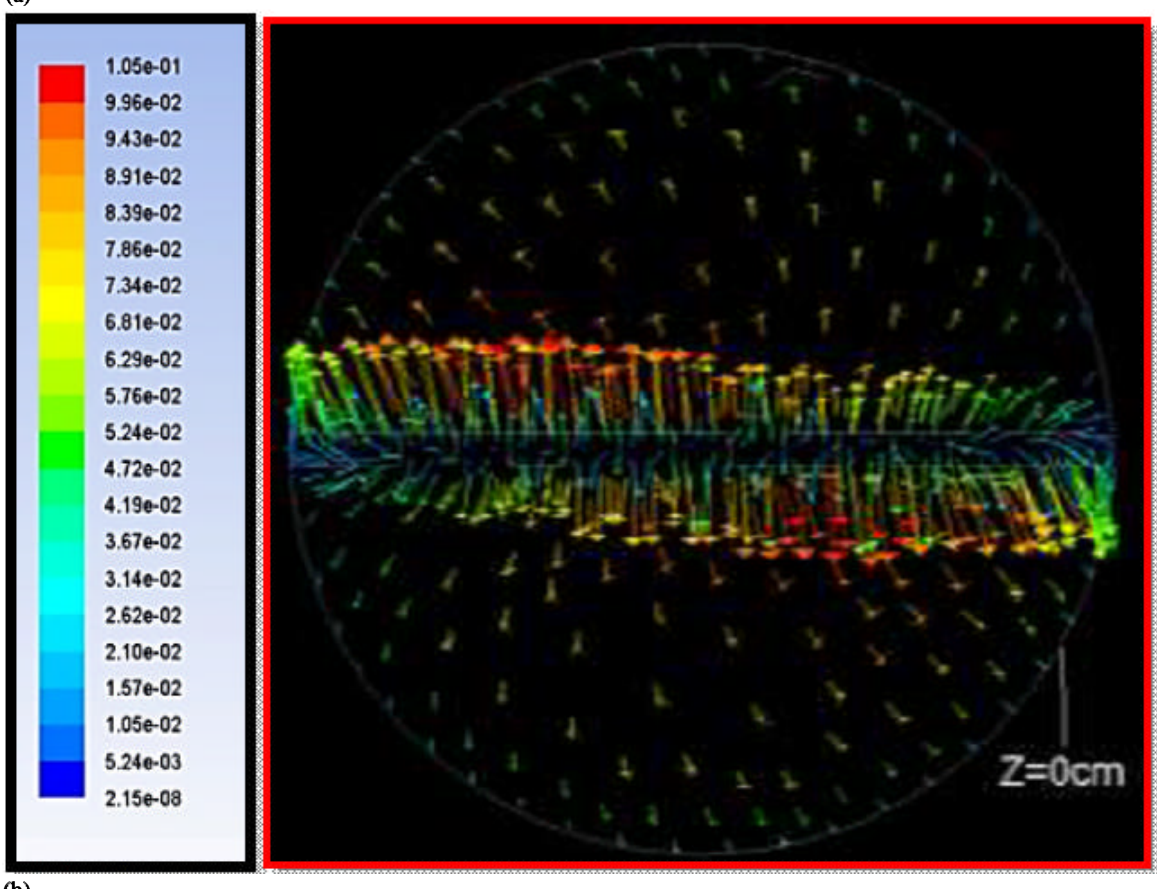

(b)

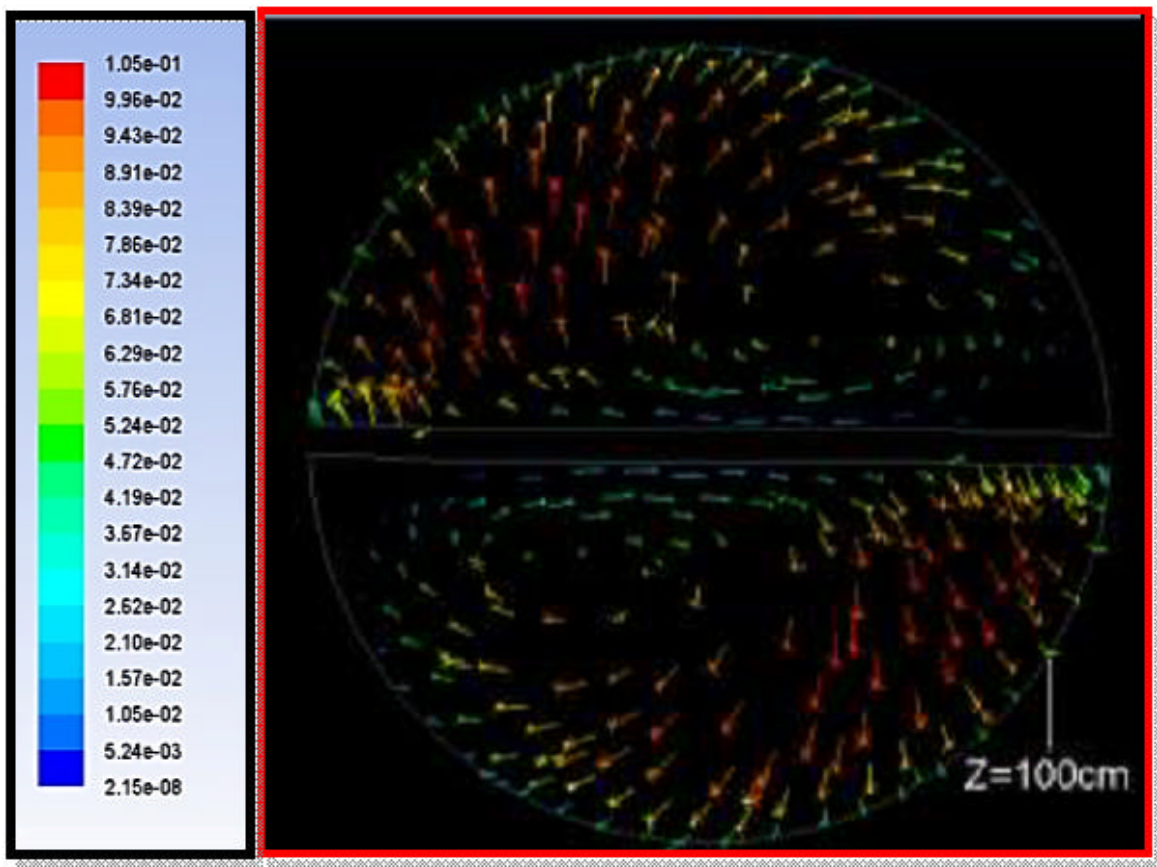

Fig. 14: a, b) Velocity vector in $(\mathrm{m} / \mathrm{sec})$ at locations of alternate axis twisted tape along the test section with $(\mathrm{Re}=2002$, $\mathrm{TR}=4)$

At section $(Z=0 \mathrm{~cm})$ the sudden impact of the flow with the twisted tape is shown and then a secondary flow induced and a rotational movement is noticed along the tube which will enhance the heat transfer in the tube. And this secondary flow will increase with decrease in twist ratio. Figure 14 shows the velocity vector at different sections along the tube. The flow passes a series of alternate axis twisted tape sections where the flow changes its direction of rotation and a stronger secondary flow is induced. 

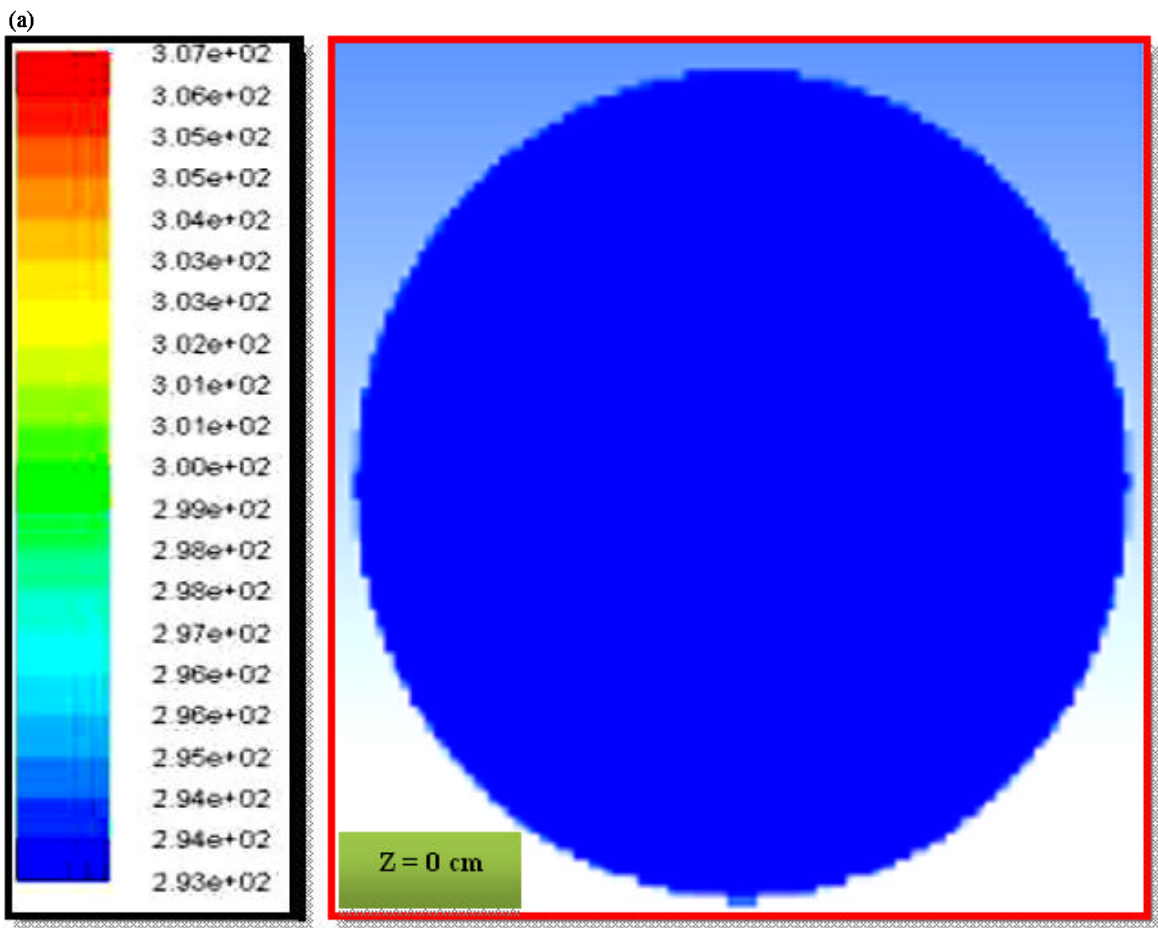

(b)

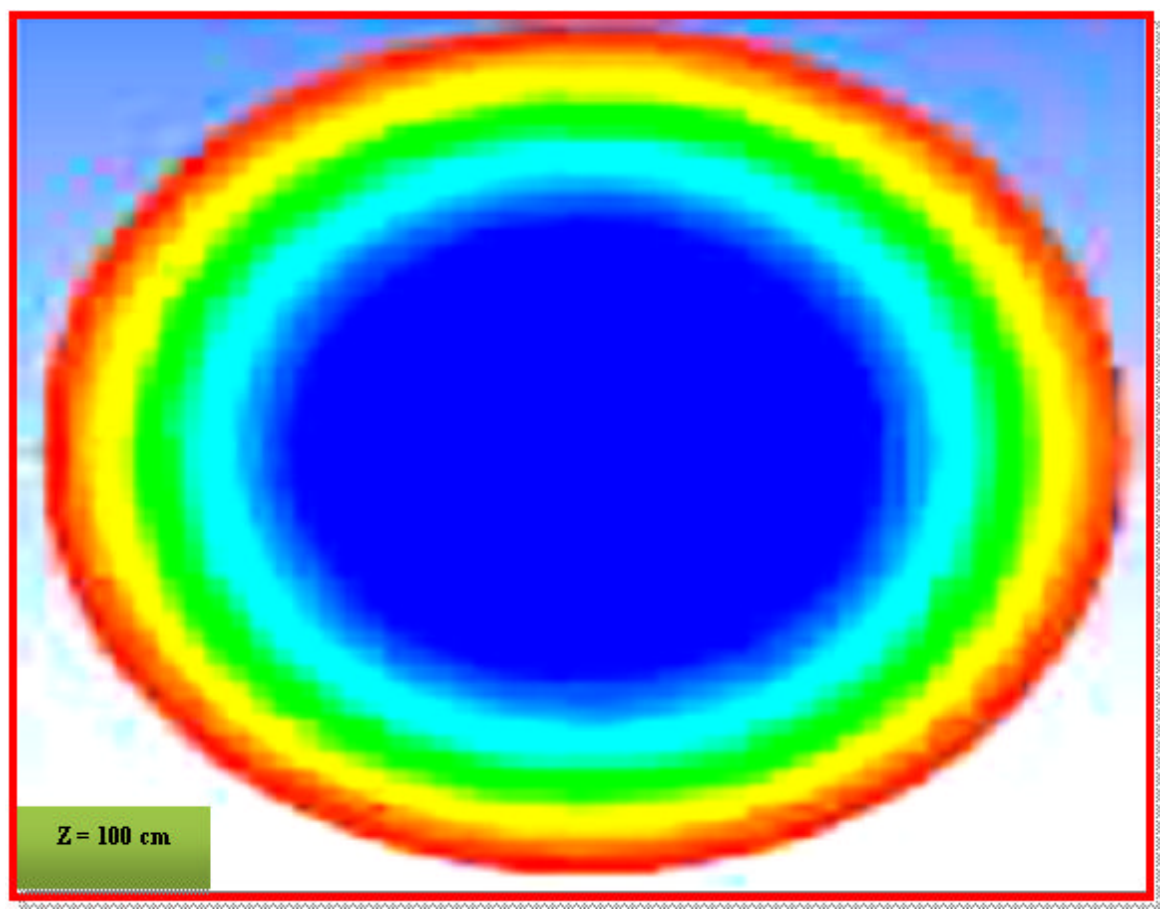

Fig. 15: a, b) Temperature contours in $(\mathrm{K})$ at locations of $(\mathrm{Z}=0,100 \mathrm{~cm})$ along the test section for plain tube with $(\operatorname{Re}=2002)$

Temperature and velocity contours: Figure $15-17$ show the temperature contours at locations of $(Z=0,100 \mathrm{~cm})$ along the test section for plain tube and $(Z=0,100 \mathrm{~cm})$ for $\mathrm{V}$-cut and alternate axis twisted tape, respectively. The temperature increases to the exit of the tube and with change of one twisted tape type. As a result of increasing the secondary flow with decreasing twist ratio or increasing Reynolds number, the temperature will 
(a)

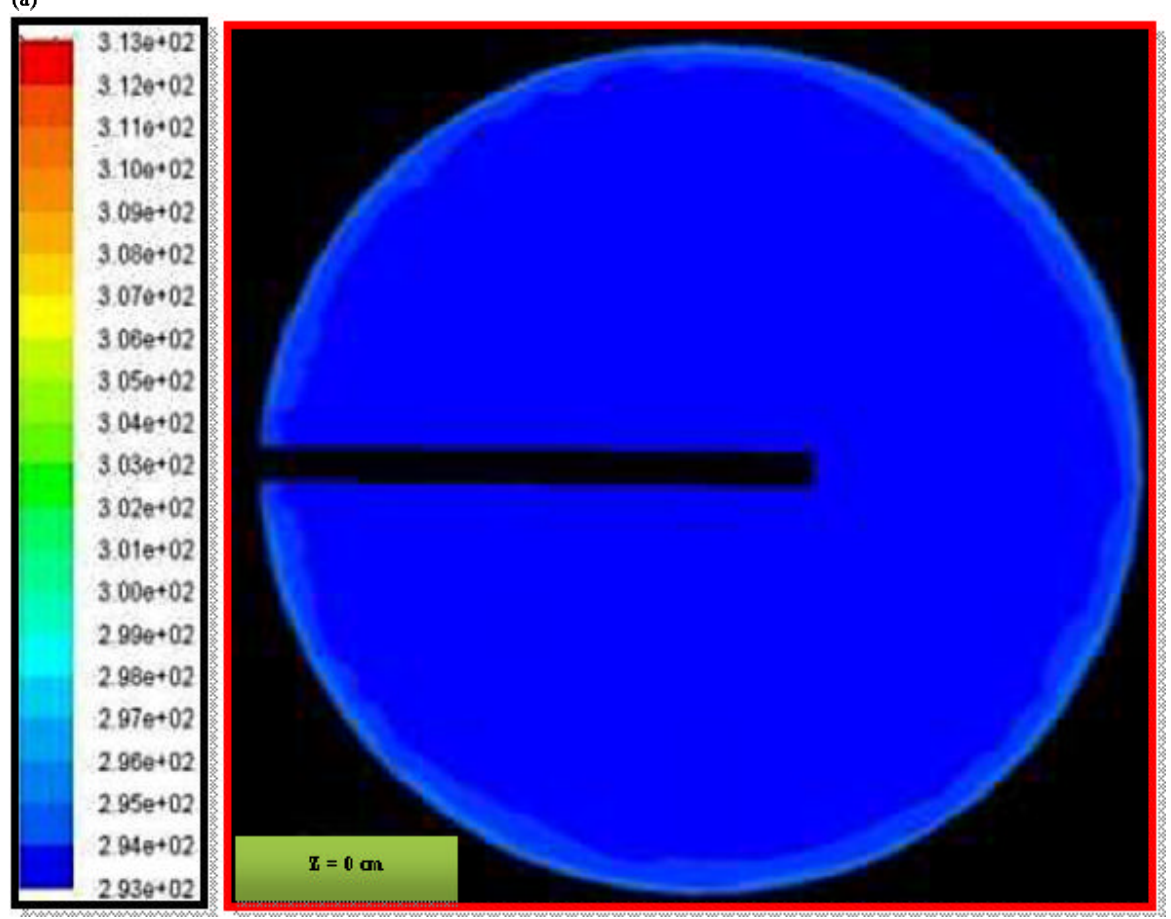

(b)

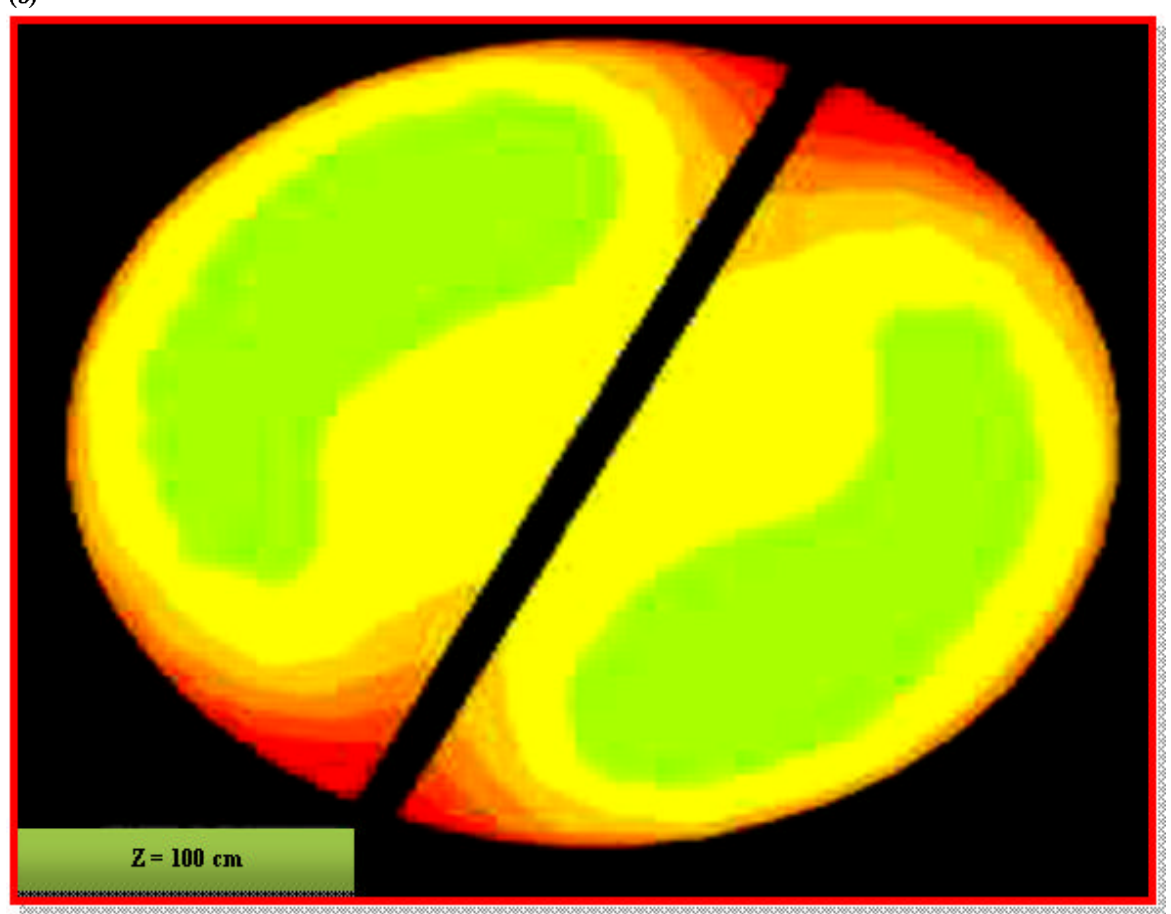

Fig. 16: a, b) Temperature contours in $(\mathrm{K})$ at locations of $(\mathrm{Z}=0,100 \mathrm{~cm})$ along the test section for $\mathrm{V}$-cut twisted tape with $(\operatorname{Re}=2002, \mathrm{TR}=4)$

increase. Figure 18 highlights velocity contours along the test section V-cut twisted tape. Higher value of (Re) produces higher velocity then higher turbulence and better heat transfer due to high mixing and good heat distribution between flow core and boundary. 
J. Eng. Applied Sci., 14 (14): 4905-4918, 2019

(a)

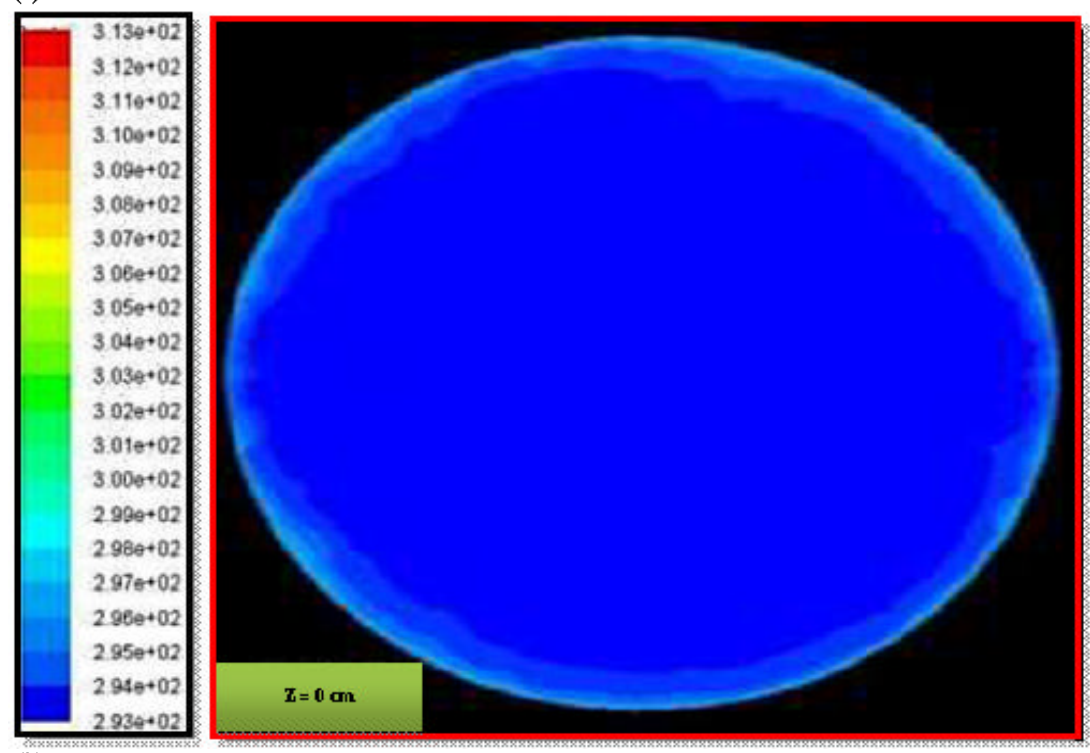

(b)

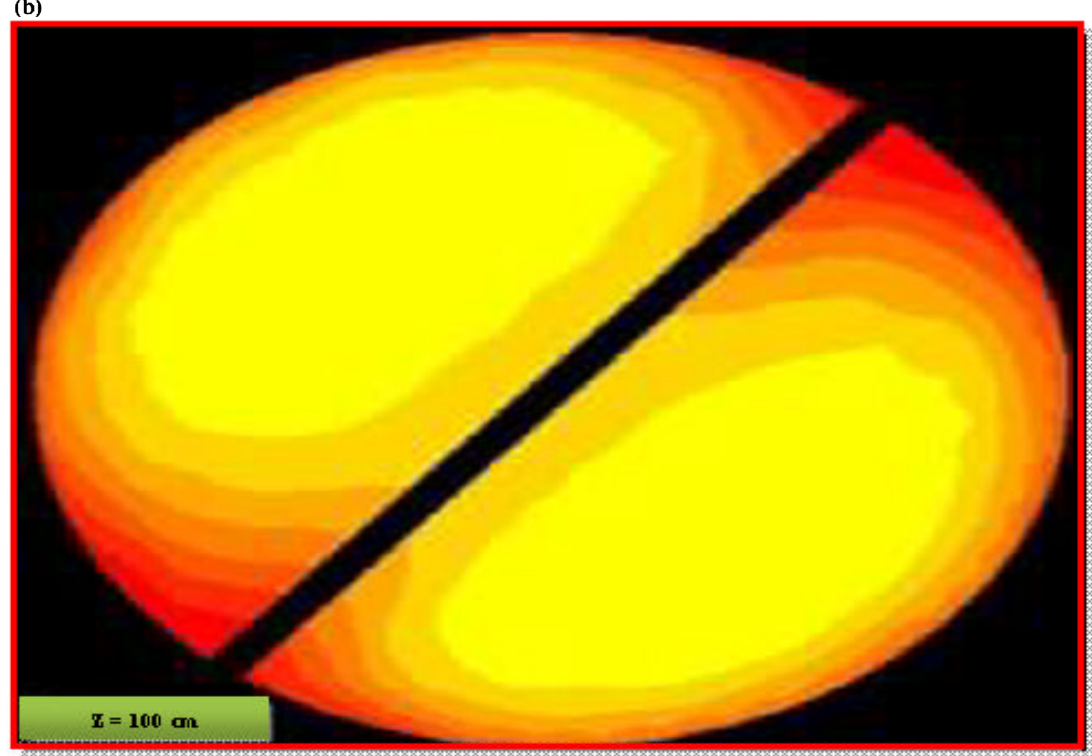

Fig. 17: a, b) Temperature contours in $(K)$ at locations of $(Z=0,100 \mathrm{~cm})$ along the test section for alternate axis with $(\operatorname{Re}=2002, T R=4)$

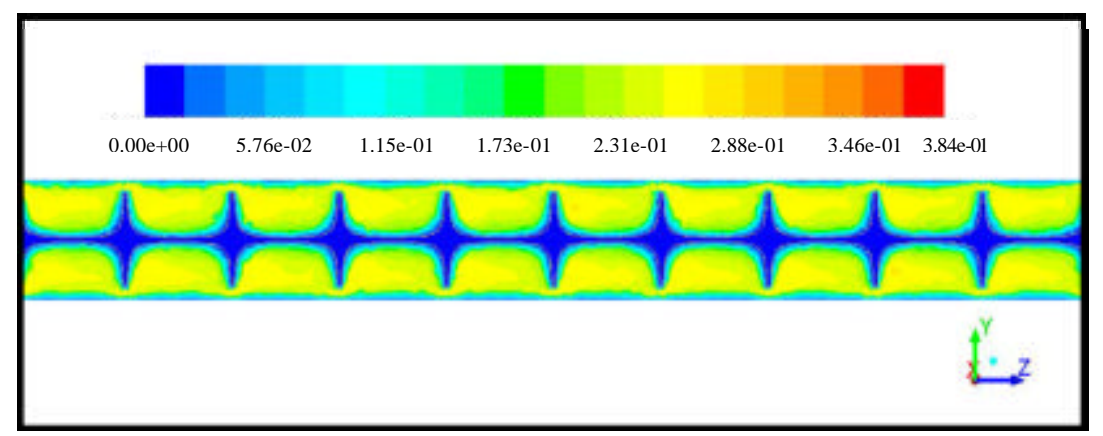

Fig. 18: Velocity contours along the test section $\mathrm{V}$-cut twisted tape with $4483 \mathrm{~W} / \mathrm{m}^{2}$ heat flux 

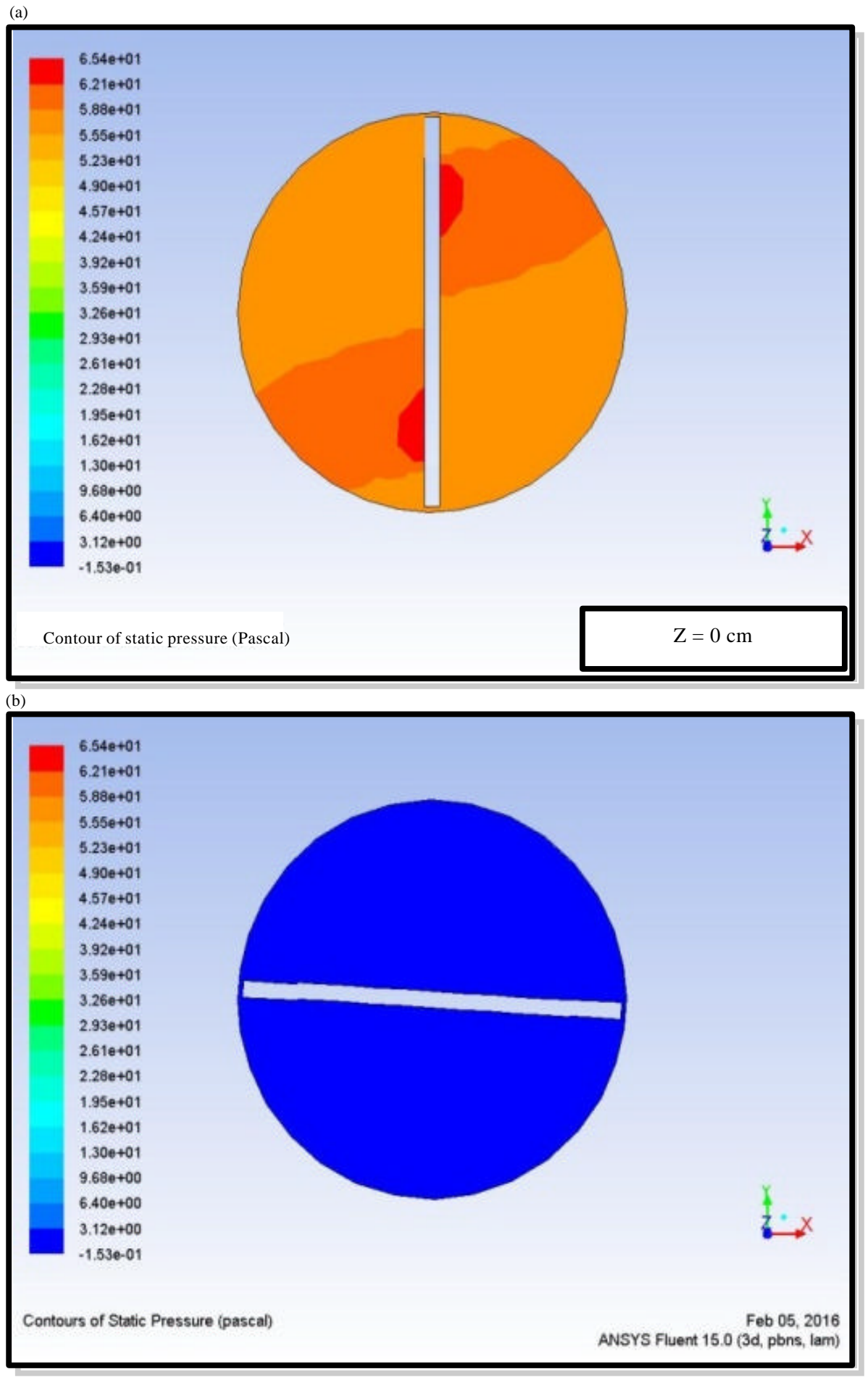

Fig. 19: a, b) Pressure contours for DI-water at various axial distances for V-cut twisted tape with $4483 \mathrm{~W} / \mathrm{m}^{2}$ heat flux

Pressure contours: Figure 19 and 20 illustrate the static pressure drop distribution contours for the V-cut and alternate axis twisted tapes insert at different axial locations along the tube. One can see in these figures that the pressure drop for distilled water flowing through the plain tube outfitted with the V-cut twisted tape is lower than that for the alternate axis twisted tape. 

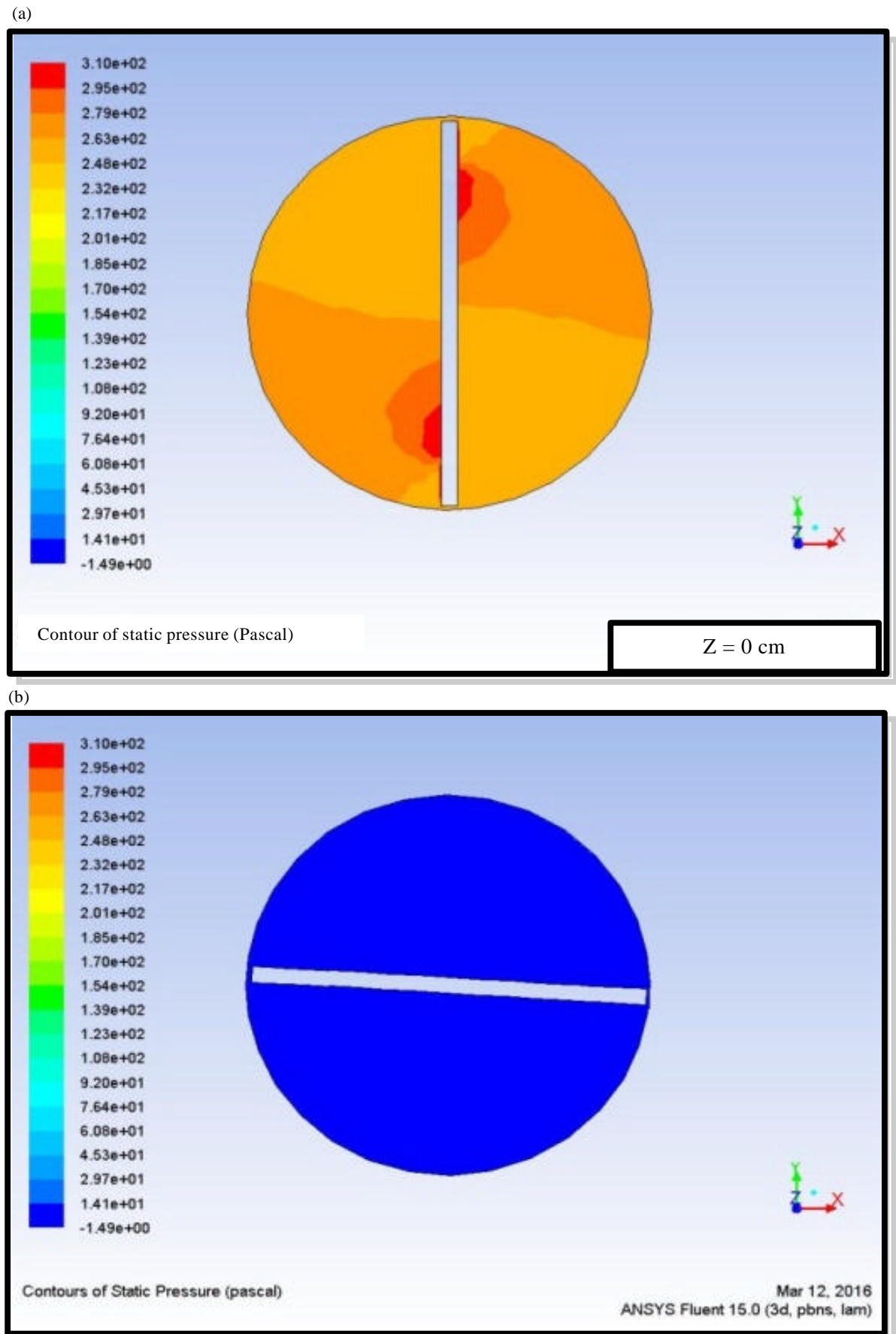

Fig. 20: a, b) Pressure contours for DI-water at various axial distances for alternate axis twisted tape with $4483 \mathrm{~W} / \mathrm{m}^{2}$ heat flux

\section{CONCLUSION}

In the present study, the influence of using variant twisted tapes (Alternate axis, V-cut twisted tape) fitted in a single horizontal tube of heat exchanger on the heat transfer and friction factor characteristics at two Twist Ratios TR $=4$ and 6 and for a wide range of Reynolds number is experimentally and numerically investigated. The variant twisted tapes are employed depending of the idea of introducing short cuts on the circumferential 
region of the tape (V-cut insert). The experiments are conducted to find the suitable tape for the industrial applications. The conclusion arrived from the present work are presented in the following: a higher heat transfer enhancement and thermal performance can be obtained by using an inserted tape with a lower twist ratio, for example, the ratio of $(\mathrm{TR}=4)$ offers a thermal enhancement almost (12.6\%) higher than that offered by the ratio of $(\mathrm{TR}=6)$.

The alternate axis insert supplies an improvement in heat transfer augmentation better than that provided by the V-cut insert. That is because of the effective secondary flow in addition with the main swirl flow.

The alternate axis produces higher thermal performance than that produced by the $\mathrm{V}$-cut insert merely at lower Twist Ratio (TR $=4)$. This is owing to the elevated degree of resulted turbulence mixing.

There is a reasonable agreement $( \pm 10 \%)$ between numerical approach and experimental results obtained from this study. Both the average Nusselt number and the friction loss increase by decreasing the twist ratio of twisted tape. The temperature of the flow increases and becomes more homogenous with increasing flow rate and decrease with the twist ratio.

\author{
Abbreviations: \\ CFD : Computational Fluid Dynamics \\ UWT : Uniform Wall Temperature \\ $\mathrm{Nu}$ : Nusselt number \\ $\mathrm{y}:$ : Twist ratio \\ $\mathrm{x}, \mathrm{y}, \mathrm{z}$ : Cartesian coordinate $(\mathrm{m})$
}

\section{ACKNOWLEDGEMENT}

Muna S. Kassim would like to thank Mustansiriyah University (www.uoustansiriyah.edu.iq), Baghdad, Iraq for its support in the present work. In addition, the other researchers thank their universities for support.

\section{REFERENCES}

Agarwal, S.K. and M.R. Rao, 1996. Heat transfer augmentation for the flow of a viscous liquid in circular tubes using twisted tape inserts. Intl. J. Heat Mass Transfer, 39: 3547-3557.
Al-Fahed, S., L.M. Chamra and W. Chakroun, 1998. Pressure drop and heat transfer comparison for both microfin tube and twisted-tape inserts in laminar flow. Exp. Therm. Fluid Sci., 18: 323-333.

Bhattacharyya, S., S. Saha and S.K. Saha, 2013. Laminar flow heat transfer enhancement in a circular tube having integral transverse rib roughness and fitted with centre-cleared twisted-tape. Exp. Therm. Fluid Sci., 44: 727-735.

Guo, J., A. Fan, X. Zhang and W. Liu, 2011. A numerical study on heat transfer and friction factor characteristics of laminar flow in a circular tube fitted with center-cleared twisted tape. Int. J. Thermal Sci., 50: 1263-1270.

Kapatkar, V.N., A.S. Padalkar and S. Kasbe, 2010. Experimental investigation on heat transfer enhancement in laminar flow in circular tube equipped with different inserts. Proc. Int. Conf. Adv. Mech. Eng., 1: 58-63.

Klaczak, A., 2000. Heat transfer by laminar flow in a vertical pipe with twisted-tape inserts. Heat Mass Transfer, 36: 195-199.

Liao, Q. and M.D. Xin, 2000. Augmentation of convective heat transfer inside tubes with three-dimensional internal extended surfaces and twisted-tape inserts. Chem. Eng. J., 78: 95-105.

Liu, S. and M. Sakr, 2013. A comprehensive review on passive heat transfer enhancements in pipe exchangers. Renew. Sustainable Energy Rev., 19: 64-81.

Rebay, S., 1993. Efficient unstructured mesh generation by means of delaunay triangulation and BowyerWatson algorithm. J. Comput. Phys., 106: 125-138.

Saha, S.K. and A. Dutta, 2001. Thermohydraulic study of laminar swirl flow through a circular tube fitted with twisted tapes. J. Heat Transfer, 123: 417-427.

Salman, S.D., A.A.H. Kadhum, M.S. Takriff and A.B. Mohamad, 2013. CFD analysis of heat transfer and friction factor characteristics in a circular tube fitted with quadrant-cut twisted tape inserts. Math. Prob. Eng., 2013: 1-8.

Zhang, X., Z. Liu and W. Liu, 2012. Numerical studies on heat transfer and flow characteristics for laminar flow in a tube with multiple regularly spaced twisted tapes. Intl. J. Therm. Sci., 58: 157-167. 